\title{
Immune response to Acinetobacter calcoaceticus infection in man
}

\author{
A. W. SMITH and K.E. ALPAR* \\ Microbiology Research Group, Pharmaceutical Sciences Institute, Aston University, Aston Triangle, Birmingham \\ B4 7ET and "Accident Hospital, Birmingham B15 6NA
}

\begin{abstract}
Summary. After growth in an iron-depleted chemically-defined medium Acinetobacter calcoaceticus expressed four high mol. wt outer-membrane proteins (OMPs) which were repressed under iron supplementation or in a complex laboratory medium. Immunoblotting with serum from a septicaemic patient infected with $A$. calcoaceticus revealed antibody binding to these iron-repressible OMPs, indicating that they were expressed in vivo, and also to the 42- and 18-Kda OMPs. Although the antibody response to the OMPs did not vary significantly during convalescence, the response to the O-polysaccharide component of lipopolysaccharide decreased significantly. However, antibodies in serum from patients with $A$. calcoaceticus wound infections reacted with the iron repressible OMPs and a 54-Kda antigen suggesting a difference in immune recognition between local and systemic infection.
\end{abstract}

\section{Introduction}

Acinetobacter strains are often found in soil and freshwater samples, and commonly constitute part of the normal human flora. ${ }^{1}$ Although many clinical isolates reflect colonisation rather than infection, an increasing number of reports ${ }^{1-7}$ suggest that Acinetobacter spp. have become important nosocomial pathogens. Patient groups most susceptible to infection are predominantly those immunocompromised through trauma, major surgery, burns or malignancies. ${ }^{1}$ The lower respiratory tract is a common site of infection, particularly in patients with tracheostomies and endotracheal tubes. ${ }^{3}$ A rapid increase in resistance of $A$. calcoaceticus, and in particular of the biovar anitratus, to many antibacterial drugs has been noted. ${ }^{2}$ However, despite increasing evidence that Acinetobacter infections are difficult to treat, there have been few reports of the host immune response to them. Brade and Galanos ${ }^{8}$ identified a lipopolysaccharide (LPS) antigen in a passive haemolysis assay. Antibodies raised in rabbits to it could be removed only partially by adsorption with enterobacterial lipid $A$, indicating the presence of an additional antigen. Antibodies to this antigen were present in different uninfected animals, including man. It has been reported that $\boldsymbol{A}$. calcoaceticus can enhance the virulence of other bacteria in mixed infections, perhaps by slime-induced inhibition of neutrophils. ${ }^{9}$ However, the mechanisms of virulence of Acinetobacter in vivo are only poorly understood.

The ability to adapt to, and multiply in, the tissues

Received 18 May 1990; accepted 9 July 1990 of the host is a pre-requisite for pathogenicity. ${ }^{10}$ Although the nature of the host environment is illdefined, it is widely recognised that for many bacterial species, in the absence of specific uptake systems, the amount of freely available iron is too small to sustain growth. ${ }^{11}$ An iron-restricted environment induces several phenotypic changes, including changes in the composition of the outer membrane (OM) of bacteria growing in vivo. ${ }^{12}$

We have shown recently that a clinical isolate of $\boldsymbol{A}$. calcoaceticus produced the iron-chelator 2,3-dihydroxybenzoic acid (DHBA) when grown in vitro in an irondepleted chemically-defined medium. ${ }^{13}$ Disk-diffusion studies with Fe-DHBA chelates showed that this compound could overcome 2,2-dipyridyl-induced growth inhibition, suggesting that it was functioning as a siderophore. A preliminary examination of Sarkosyl-insoluble OM fractions revealed several proteins of $77-87 \mathrm{Kda}$, which were repressed under iron-replete growth conditions.

In this report we characterise further the phenotypic changes in the OM in response to growth in irondepleted media and examine the human immune response to both protein (OMP) and LPS components. We report the presence of $\mathrm{IgG}$ antibodies against the iron-regulated outer-member proteins (IROMPs) and the other major OMPs.

\section{Materials and methods}

\section{Bacterial strains and growth conditions}

A. calcoaceticus strains 1-11 from blood and 1-12, $1-13,1-14,1-15$ and $1-16$ from wounds were isolated 
from infected patients at the Queen Elizabeth Hospital and the Accident Hospital, Birmingham. Strains were routinely maintained on nutrient-agar slopes at $4^{\circ} \mathrm{C}$ and cultured in either a modified iron-depleted chemically-defined medium $(\mathrm{CDM}-\mathrm{Fe})^{14}(\mathrm{pH} 7 \cdot 4)$ consisting of: $40 \mathrm{mM}$ glucose; $0.62 \mathrm{mM} \mathrm{KCl} ; 0.5 \mathrm{mM}$ $\mathrm{NaCl} ; 3.2 \mathrm{mM} \mathrm{K}_{2} \mathrm{HPO}_{4} ; 40 \mathrm{mM}\left(\mathrm{NH}_{4}\right)_{2} \mathrm{SO}_{4} ; 0.4 \mathrm{mM}$ $\mathrm{MgSO}_{4} ; 50 \mathrm{~mm}$ 3-(N-morpholino) propane sulphonic acid ; and arginine, aspartic acid, proline and glutamic acid each at $100 \mu \mathrm{g} / \mathrm{ml}$; or in chelex-treated tryptone soy broth (TSB-Fe). ${ }^{15}$ Iron-replete bacteria were those grown in TSB - Fe or CDM-Fe supplemented with $1 \mu \mathrm{MeSO}_{4}(\mathrm{TSB}+\mathrm{Fe}$ or $\mathrm{CDM}+\mathrm{Fe})$. Bacteria were grown in $\mathrm{TSB}+\mathrm{Fe}, \mathrm{TSB}-\mathrm{Fe}, \mathrm{CDM}+\mathrm{Fe}$ and $\mathrm{CDM}-\mathrm{Fe}$ to early stationary phase $\left(\mathrm{E}_{470} 0.9\right)$ in an orbital shaking incubator at $37^{\circ} \mathrm{C}$, harvested by centrifugation at $10000 \mathrm{~g}$ for $10 \mathrm{~min}$ and washed once with saline.

\section{Preparation of outer membranes}

The washed bacterial pellet was resuspended in $20 \mathrm{ml}$ of distilled water and broken by 1060 -s pulses of sonication in an ice bath, with 60-s intervals for cooling. Unbroken cells were removed by centrifugation at $10000 \mathrm{~g}$ for $10 \mathrm{~min}$. Sarkosyl (sodium N-lauryl sarcosinate, Sigma) was added to the supernate to a final concentration of $2 \% \mathrm{w} / \mathrm{v}$. The mixture was incubated for $1 \mathrm{~h}$ at room temperature and then centrifuged at $100000 \mathrm{~g}$ for $1 \mathrm{~h} .{ }^{16}$ The OM pellets were washed twice by resuspension in distilled water and centrifugation at $100000 \mathrm{~g}$ for $1 \mathrm{~h}$ and were stored at $-20^{\circ} \mathrm{C}$.

\section{Sodium dodecyl sulphate-polyacrylamide gel electrophoresis (SDS-PAGE)}

OM preparations were electrophoresed according to the method of Lugtenberg et al. ${ }^{17}$ as modified by Anwar et al. ${ }^{18}$ on acrylamide $12 \%$ w/v gels. Each lane was loaded with c. $2.5 \mu \mathrm{g}$ of protein. For visualisation of LPS antigenic sites, OMs were heated at $100^{\circ} \mathrm{C}$ for $10 \mathrm{~min}$ in denaturing buffer containing SDS $2.5 \% \mathrm{w} / \mathrm{v}$ and 2-mercaptoethanol $2 \% \mathrm{v} / \mathrm{v}$, cooled and then incubated with proteinase K $(1 \mathrm{mg} / \mathrm{ml}$, Sigma) for $60 \mathrm{~min}$ at $60^{\circ} \mathrm{C}$ before electrophoresis. Separated OMPs were either stained with Coomassie Blue R-250 $0 \cdot 1 \% \mathrm{w} / \mathrm{v}$ in methanol:acetic acid:water $50: 10: 40$ or used for immunoblotting. Separated LPS was used for immunoblotting only.

\section{Immunoblotting}

OMPs or LPS separated on polyacrylamide gels were transferred to nitrocellulose (NC) paper and the antigens were visualised by a modification of the method of Towbin et al. ${ }^{19}$ The NC paper was incubated at room temperature in Tris-buffered saline with Tween (TBS-Tween) for $1 \mathrm{~h}$ to saturate nonspecific binding sites and then incubated overnight at $4^{\circ} \mathrm{C}$ with serum diluted 1 in 50 in TBS-Tween. The
NC paper was washed thoroughly with TBS and incubated for $2 \mathrm{~h}$ at $37^{\circ} \mathrm{C}$ with protein A-alkaline phosphatase (Sigma) $0.5 \mu \mathrm{g} / \mathrm{ml}$ in TBS-Tween. After incubation, the NC paper was thoroughly washed again. The antibody binding sites were visualised with 5-bromo-4-chloro-3-indolyl phosphate (BCIP, Sigma) and nitro-blue tetrazolium (NBT, Sigma) in accordance with the manufacturer's instructions. As a control, replicate NC transfers were stained with amido black $1 \% \mathrm{w} / \mathrm{v}$ in methanol $10 \% \mathrm{w} / \mathrm{v}$ and acetic acid $7 \% \mathrm{v} / \mathrm{v}$ to show qualitative transfer of all proteins from the acrylamide gel to the NC paper; the NC replicates were used to identify the protein bands.

\section{Serum}

Blood was taken by venepuncture from patients infected with $A$. calcoaceticus. It was allowed to clot at $37^{\circ} \mathrm{C}$ for $2 \mathrm{~h}$. After centrifugation at $2000 \mathrm{~g}$ for $10 \mathrm{~min}$, the serum was collected and stored at $-20^{\circ} \mathrm{C}$.

\section{Results}

\section{Effect of iron-depleted growth on A. calcoaceticus OMPs}

The SDS-PAGE OMP profiles of $A$. calcoaceticus strain 1-11 grown in TSB + Fe (lane 1), TSB - Fe (lane 2), $\mathrm{CDM}+\mathrm{Fe}$ (lane 3) and CDM - Fe (lane 4) are shown in fig. 1. The synthesis of four OMPS of 77, 78, 84 and $87 \mathrm{Kda}$ was strongly induced in the OM of cells grown in CDM-Fe (lane 4). This did not occur to any significant extent in cells grown in either CDM+

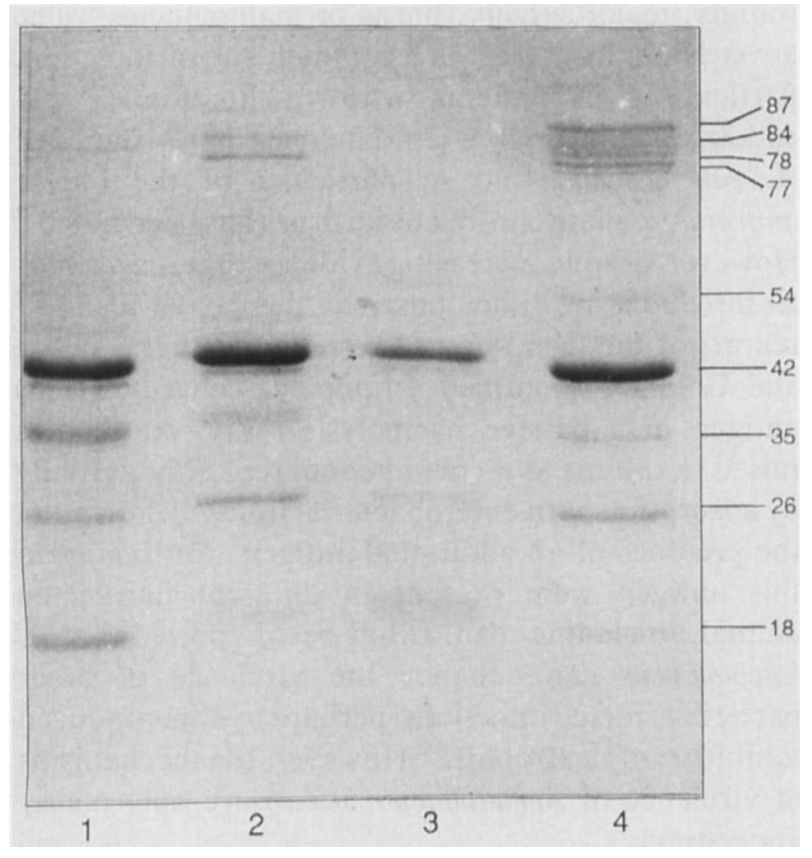

Fig. 1. SDS-PAGE of OMPs of $A$. calcoaceticus strain 1-11 grown in TSB + Fe (lane 1), TSB-Fe (2), CDM + Fe (3) and CDM - Fe (4) OMPs were stained with Coomassie Blue. Numbers refer to mol. wts (Kda). 
Fe (lane 3) or TSB + Fe (lane 1). These four proteins were also detected in the OM of cells grown in TSB $\mathrm{Fe}$ (lane 2), although the 84-Kda OMP was not strongly expressed. Similar experiments with magnesiumlimited cultures did not induce the expression of these four proteins (results not shown). These data indicate that expression of the four OMPs is not the result of poor growth in a defined medium, but rather that it arose from the specific depletion of iron. Iron depletion had no major effect on the expression of the other major OMPs of 54, 42, 35, 26 and $18 \mathrm{Kda}$. Similar OMP profiles were found with the other five clinical isolates of $A$. calcoaceticus.

\section{Antibody response to A. calcoaceticus $O M$ components}

The antigens of $A$. calcoaceticus recognised by IgG antibodies in the serum of the patient 10 days after diagnosis of septicaemia are shown in fig. 2. IgG antibodies strongly recognised the $78-$ and $87-\mathrm{Kda}$ IROMPs in A. calcoaceticus grown in conditions of iron depletion (lanes 2 and 4 ) but these antigens were undetectable or only barely detectable in iron replete cells (lanes 1 and 3). Of the lower mol. wt OMPs, only the 42 - and $18-\mathrm{Kda}$ proteins reacted strongly with IgG antibodies.

Strip immunoblotting was performed to measure any changes in antibody response during post-infection convalescence. Serum samples were taken up to

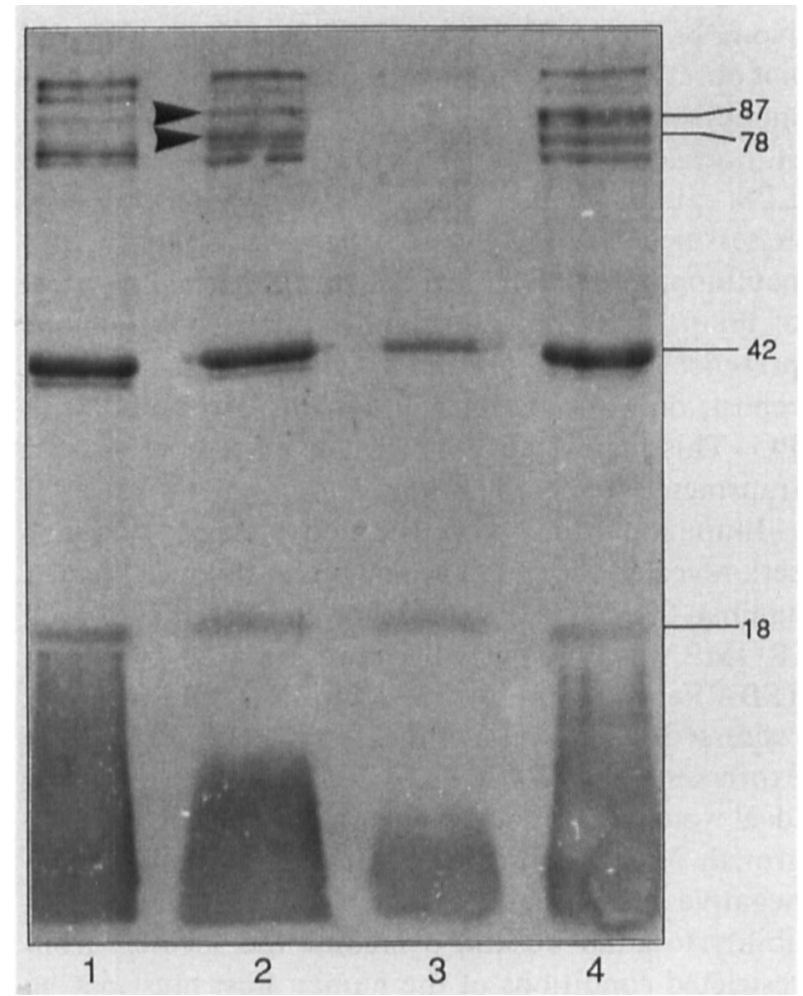

Fig. 2. Immunoblot of the OMPs in fig. 1 (lanes 1-4 as described) probed with serum from patient $1-11$, obtained 10 days after diagnosis of septicaemia. Reactions were visualised with alkaline phosphatase-conjugated $S$. aureus protein A. Numbers refer to mol. wts (Kda).
54 days after diagnosis of septicaemia. The IgG antibody response with time to OMPs of $A$. calcoaceticus strain 1-11 grown in $\mathrm{CDM}-\mathrm{Fe}$ is shown in fig. 3A. No major differences were seen although an increased response with time to a 100-Kda OMP was noted. The IgG anti-LPS activity against the same $\mathrm{OM}$ preparation, but after proteinase $\mathrm{K}$ digestion, is shown in fig. 3B. Strong responses to both the Opolysaccharide and core/lipid A LPS components were noted at diagnosis. These were greatly diminished during recovery from infection, particularly in the sample taken 54 days after diagnosis.

An immunoblot of the other five clinical isolates of A. calcoaceticus from patients with local wound infections is shown in fig. 4. The isolates were grown in $\mathrm{CDM}-\mathrm{Fe}$ and the $\mathrm{NC}$ paper containing the electrophoresed OMPs was subsequently incubated with serum from one of the patients (1-12) taken 10 days after diagnosis of infection. The 87-Kda IROMP from all five isolates together with the 54-Kda OMP were strongly recognised by IgG antibodies. The 42Kda OMP was detected only weakly. Essentially
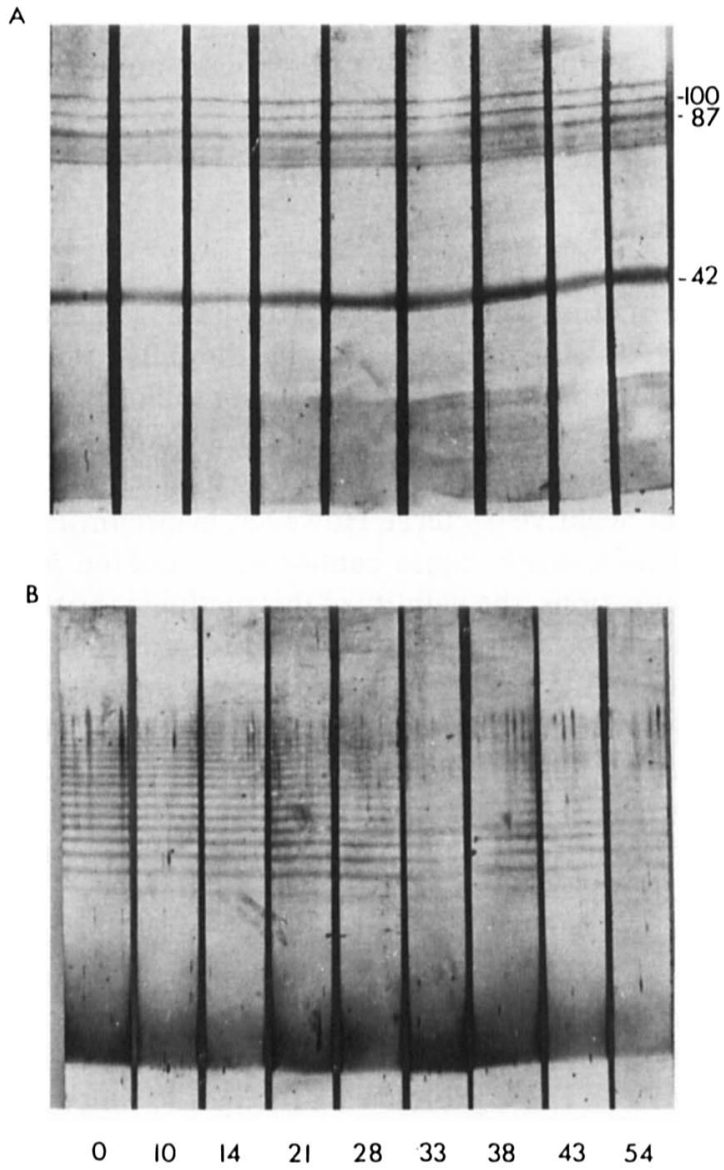

\section{Days after diagnosis}

Fig. 3. Strip immunoblot of OMPs (A) and LPS(B) of $A$. calcoaceticus strain 1-11 cultivated in CDM - Fe and probed with serum from patient 1-11, obtained at various time intervals after diagnosis of infection. Reactions were visualised with alkaline phosphataseconjugated $S$. aureus protein A. Numbers refer to mol. wts (Kda). 


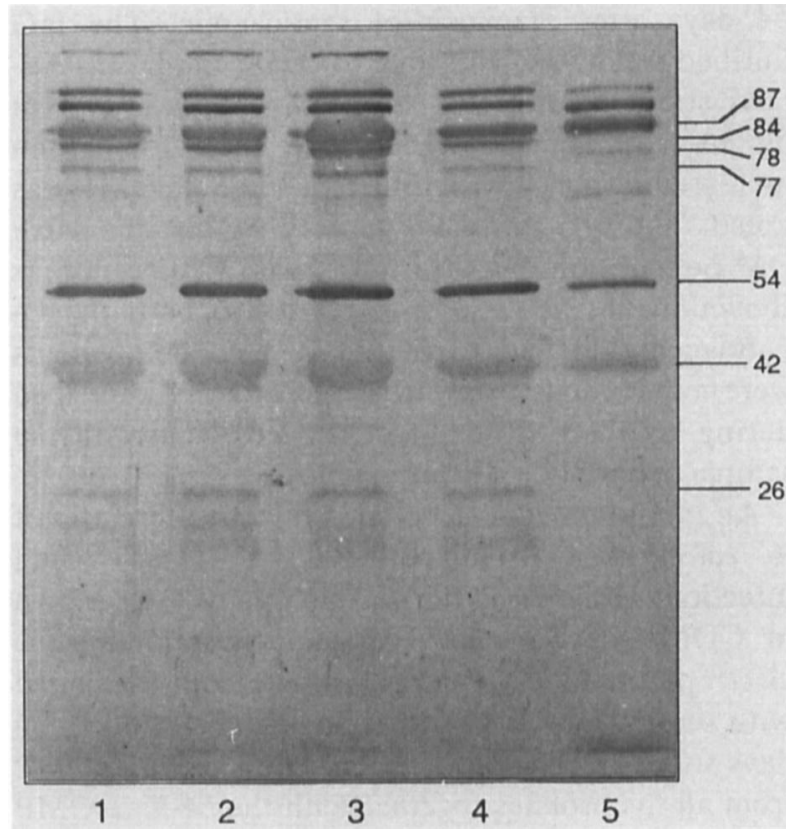

Fig. 4. Immunoblot of OMPs of clinical isolates of $A$. calcoaceticus from local wounds of patient 1-12 (lane 1), 1-13 (2), 1-14 (3), 1-15 (4) and 1-16 (5) grown in CDM - Fe and probed with serum from patient 1-14 obtained 10 days after onset of infection. Numbers refer to mol. wts (Kda).

similar results were noted with replicate immunoblots probed with sera from the other patients.

\section{Discussion}

Information concerning both the pathogenic mechanisms of $A$. calcoaceticus and the host immune response to infection is scant. Immunoblotting techniques are used widely to determine antibody responses to cellular components, particularly the OM of gram-negative bacteria. However, in circumstances where sufficient bacteria cannot be recovered in situ from infections, the validity of this method is critically dependent on how the organisms are grown in vitro. Indeed, such results may be misleading in light of the well known phenotypic plasticity of the bacterial envelope. ${ }^{12}$ The results of this investigation indicated clearly that $\boldsymbol{A}$. calcoaceticus responded to iron-depleted growth conditions by inducing the expression of 77 87-Kda OMPs which were repressed under iron replete conditions. Although a new finding for A. calcoaceticus, it was not surprising. A large number of different bacteria have been shown to adapt to iron-restricted conditions by synthesising one or more high mol. wt IROMPs. ${ }^{11}$ These proteins are thought to function as receptors to facilitate the internalisation of $\mathrm{Fe}$ siderophore complexes, and this has been proven for certain bacteria, notably $E$. coli. ${ }^{20}$ In a previous report $^{13}$ we showed that $A$. calcoaceticus produced 2,3dihydroxybenzoic acid (DHBA) when grown under iron-depleted conditions and this functioned as a siderophore. These data led us to suggest that one or more of the high mol. wt IROMPs might be a receptor for this siderophore. At this stage it is not clear whether A. calcoaceticus can utilise siderophore molecules only produced by itself or whether it can acquire iron from exogenously supplied siderophores. Such a situation would be analogous to $E$. coli using the fungal siderophore ferrichrome via the 78-K da Fhu IROMP receptor. ${ }^{21}$ Interestingly, it has been shown recently that $E$. coli is able to take up Fe-DHBA via Fiu and $C$ ir receptors, and less efficiently via the $F e p A$ receptor, indicating a lack of absolute receptor specificity in this species. ${ }^{22}$ The demonstration of siderophore production in $A$. calcoaceticus provides an interesting contrast with that of the other members of the Neisseriaceae that are capable of removing iron from host binding proteins by a siderophore-independent mechanism. ${ }^{23}$.

With the exception of the high mol. wt IROMPs identified in this study, the lower mol. wt OMPS were of a similar size to those of Acinetobacter SP. FO-1 and $A$. calcoaceticus ATCC $23055^{24}$ and $A$. calcoaceticus $69 \mathrm{~V} .{ }^{25}$ The cell envelope profiles of the six clinical isolates in this study did not exhibit the marked heterogeneity reported by Dijkshoorn et al. ${ }^{26}$ in their study of 78 clinical isolates. The OMP profiles appear similar to the "pattern D" established by these workers. The similarity of OMP profiles with those published previously confirms the usefulness of sarkosyl extraction to prepare $A$. calcoaceticus OMs. In agreement with Nishimura et al. ${ }^{24}$ we found that the major 42-Kda OMP was heat modifiable, as was the 26-Kda OMP. Both proteins appeared in their fully modified form after treatment at $100^{\circ} \mathrm{C}$ for $10 \mathrm{~min}$. None of the IROMPs was heat modifiable. We did not observe with the clinical isolates in this study heat modification of the 18-Kda OMP in contrast to that in A. calcoaceticus $69 \mathrm{~V} .^{25}$ This OMP also interacts with LPS, although the affinity is strain-dependent. ${ }^{25}$ Assessment of the non-covalent association with peptidoglycan (PG) was made by measuring the effect of temperature on the solubilisation of OMs in the presence of SDS. Of the OMPs identified in this report, only the 42-Kda OMP was associated with PG. This feature suggests that it may function as a transmembrane pore protein.

Immunoblotting with the convalescent patient's sera revealed the presence of IgG antibodies directed against the IROMPs and showed that the $87-\mathrm{Kda}$ IROMP was only partially repressed after growth in $\mathrm{TSB}+\mathrm{Fe}$, whereas the $77-\mathrm{Kda}$ IROMP was fully repressed. These data indicate that $A$. calcoaceticus expresses these IROMPs in vivo in septicaemia and local wound infections. This finding of iron-restricted growth in vivo is a common feature of many gramnegative bacterial infections. ${ }^{18,27-33}$ However, this ability to adapt to and overcome the severely ironrestricted conditions of the human host must not be overlooked as an important determinant of virulence and disease pathogenesis for $\boldsymbol{A}$. calcoaceticus.

Our immunoblotting studies did not indicate any significant differences in the antibody response to 
OMPs during convalescence. The particularly strong response found with the "pre-immune" serum sample taken at diagnosis of septicaemia can be interpreted in two ways. Firstly, the patient may have been exposed to $A$. calcoaceticus prior to diagnosis of septicaemia, by, for example, a sub-clinical local infection, and therefore have already started to generate an immune response, or, secondly, the organism may have been part of the normal human flora. When pooled serum was taken from 20 healthy subjects and used in immunoblotting studies, a weak IgG antibody response to the major OMPs was noted, probably reflecting the colonisation of a proportion of the population. ${ }^{1}$ The IgG anti-LPS response decreased during the convalescent period. Interestingly, our immunoblotting studies revealed the presence of $\mathrm{O}$ polysaccharide bands in OMs after digestion with proteinase $\mathrm{K}$. This finding of smooth-type LPS is in contrast to the R-like LPS isolated from strain Acinetobacter NCTC $10305 .{ }^{34}$ It is not clear whether the structure of LPS varies between strains or depends on the method of preparation. It is possible that the immunoblotting technique affords a greater limit of detection than silver staining.

During this study an interesting difference between the immune response to a local infection and septicaemia became apparent. The IROMPs were detected in both cases. However, in septicaemia, only the 42- and 18-Kda OMPs were detected, whereas with a local infection, the 54-Kda OMP was the major antigen and the 42-and 18-Kda OMPs were only weakly detectable. Caution must be exercised in interpreting the data in this study from only one septicaemic patient. However, it may prove possible to distinguish colonisation or local infection from septicaemia on the basis of the immune response. Furthermore, the immunoblotting study of serum from one locally-infected patient against the OMs from five wound isolates indicates that the major OMPs are immunlogically crossreactive.

Our finding that $\boldsymbol{A}$. calcoaceticus expresses several IROMPs when grown under iron-depleted conditions in vitro and that these IROMPs are recognised by IgG antibodies in convalescent sera from infected patients, suggests that they are expressed in vivo. Of all growth requirements known, iron is probably the most thoroughly studied. Further work is required to determine whether other components, yet to be identified, such as extracellular virulence factor production are iron-regulated and what are the functions of the anti-IROMP antibodies. Such studies should improve our knowledge of this important nosocomial pathogen.

We gratefully acknowledge helpful discussions with Professor M. Brown and Dr P. Lambert. This work was supported in part by the Medical Research Council.

\section{References}

1. Bergogne-Bérézin E, Joly-Guillou ML, Vieu JF. Epidemiology of nosocomial infections due to Acinetobacter calcoaceticus. $J$ Hosp Infect 1987; 10: 105-113.

2. Berogogne-Bérézin E, Joly-Guillou ML. An underestimated nosocomial pathogen, Acinetobacter calcoaceticus. J Antimicrob Chemother 1985; 16: 535-538.

3. Buxton AE, Anderson RL, Werdegar D, Atlas E. Nosocomial respiratory tract infection and colonization with Acinetobacter calcoaceticus. Am J Med 1978; 65: 507-513.

4. Sherertz RJ, Sullivan ML. An outbreak of infections with Acinetobacter calcoaceticus in burn patients: contamination of patients' mattresses. J Infect Dis 1985; 151 : 252-258.

5. Smego RA. Endemic nosocomial Acinetobacter calcoaceticus bacteremia. Arch Intern Med 1985; 145: 2174-2179.

6. Vila J, Almela M, Jimenez de Anta MT. Laboratory investigation of hospital outbreak caused by two different multiresistant Acinetobacter calcoaceticus subsp. anitratus strains. $J$ Clin Microbiol 1989; 27: 1086-1089.

7. Ygout J-F, Housset B, Derenne J-P, Dagnet G-L. Hospitalacquired Acinetobacter baumannii pneumonitis. Lancet $1987 ; 1: 802$.

8. Brade H, Galanos C. A new lipopolysaccharide antigen identified in Acinetobacter calcoaceticus: occurrence of widespread natural antibody. $J$ Med Microbiol 1983; 16: 203-210.

9. Obana Y.Pathogenic significance of Acinetobacter calcoaceticus: analysis of experimental infection in mice. Microbiol Immunol 1986; 30: 645-657.

10. Smith H. Pathogenicity and the microbe in vivo. J Gen Microbiol $1990 ; 136: 377-383$.

11. Griffiths E. The iron-uptake systems of pathogenic bacteria. In: Bullen JJ, Griffiths E (eds) Iron and infectionmolecular, physiological and clinical aspects. Chichester, John Wiley and Sons. 1987: 69-138.

12. Brown MRW, Williams P. The influence of environment on

envelope properties affecting survival of bacteria in infections. Ann Rev Microbiol 1985; 39: 527-556.

13. Smith AW, Freeman S, Minett WG, Lambert PA. Characterisation of a siderophore from Acinetobacter calcoaceticus. FEMS Microbiol Lett 1990; 70: 29-32.

14. Brown MRW, Anwar H, Lambert PA. Evidence that mucoid Pseudomonas aeruginosa in the cystic fibrosis lung grow under iron-restricted conditions. FEMS Microbiol Lett 1984; 21 : 113-117.

15. Kadurugamuwa JL, Anwar H, Brown MRW, Shand GH, Ward $\mathrm{KH}$. Media for study of growth kinetics and envelope properties of iron-deprived bacteria. J Clin Microbiol 1987; 25: 849-855.

16. Filip C, Fletcher G, Wulff JL, Earhart CF. Solubilization of the cytoplasmic membrane of Escherichia coli by the ionic detergent sodium lauryl sarcosinate. J Bacteriol 1973 ; 115: 717-722.

17. Lugtenberg B, Miejers J, Peters R, van der Hoek P, van Alphen L. Electrophoretic resolution of the "major outer membrane protein" of Escherichia coli $\mathrm{K} 12$ into four bands. FEBS Lett 1975; 58: 254-258.

18. Anwar H, Brown MRW, Day A, Weller PH. Outer membrane antigens of mucoid Pseudomonas aeruginosa isolated directly from the sputum of a cystic fibrosis patient. FEMS Microbiol Lett 1984: 24 : 235-239.

19. Towbin H, Staehelin T, Gordon J. Electrophoretic transfer of proteins from polyacrylamide gels to nitrocellulose sheets; procedure and some applications. Proc Natl Acad Sci USA $1979 ; 76: 4350-4354$.

20. Bagg A, Neilands JB. Molecular mechanism of regulation of siderophore-mediated iron assimilation. Microbiol Rev 1987; 51: 509-518.

21. Braun V, Hantke $\mathrm{K}$, Eick-Helmerich $\mathrm{K}$ et al. Iron transport systems in Escherichia coli. In; Winkelmann G, van der Helm D, Neilands JB (eds) Iron transport in microbes, plants and animals. Weinhein, VCH. 1987: 35-51.

22. Hantke K. Dihydroxybenzoylserine-a siderophore for $E$. coli. FEMS Microbiol Lett 1990; 67: 5-8. 
23. Mickelson PA, Sparling PF. Ability of Neisseria gonorrhoeae, Neisseria meningitidis and commensal Neisseria species to obtain iron from transferrin and iron compounds. Infect Immun 1981 ; 33: 555-564.

24. Nishimura $Y$, Ino $T$, lizuka $\mathbf{H}$. Isolation and characterization of the outer membrane of radiation-resistant Acinetobacter SP. FO-1. J Gen Appl Microbiol 1986; 32: 177-184.

25. Borneleit $\mathbf{P}$, Blechschmidt $B$, Kleber H-P. Interactions between lipopolysaccharide and outer membrane proteins of Acinetobacter calcoaceticus studied by an affinity electrophoresis system. Electrophoresis $1989 ; 10$ : 234-237.

26. Dijkshoorn L, Michel MF, Degener JE. Cell envelope protein profiles of Acinetobacter calcoaceticus strains isolated in hospitals. J Med Microbiol 1987; 23: 313-319.

27. Anwar H, Shand GH, Ward KH, Brown MRW, Alpar KE, Gowar J. Antibody response to acute Pseudomonas aeruginosa infection in a burn wound. FEMS Microbiol Lett 1985 ; 29: 225-230.

28. Carniel E, Antoine J-C, Guiyoule A, Guiso N, Mollaret HH. Purification, location and immunological characterization of the iron-regulated high-molecular-weight proteins of the highly pathogenic yersiniae. Infect Immun 1989; 57: 540545
29. Deneer HG, Potter AA. Iron-repressible outer-membrane proteins of Pasteurella haemolytica. J Gen Microbiol 1989; 135: 435-443.

30. Deneer HG, Potter AA. Effect of iron restriction on outer membrane proteins of Actinobacillus (Haemophilus) pleuropneumoniae. Infect Immun 1989; 57: 798-804.

31. Fernandez-Beros ME, Gonzalez C, McIntosh MA, Cabello FC. Immune resonse to the iron-deprivation-induced proteins of Salmonella typhi in typhoid fever. Infect Immun 1989; 57: $1271-1275$.

32. Griffiths E, Stevenson P, Joyce P. Pathogenic Escherichia coli express new outer membrane proteins when growing in vivo. FEMS Microbiol Lett 1983; 16: 95-99.

33. Ward KH, Anwar H, Brown MRW, Wale J, Gowar J. Antibody response to outer-membrane proteins of Pseudomonas aeruginosa in human burn wound infection. J Med Microbiol $1988 ; 27: 179-190$.

34. Brade $\mathbf{H}$, Galanos C. Isolation, purification, and chemical analysis of the lipopolysaccharide and lipid A of Acinetobacter calcoaceticus NCTC 10305. Eur J Biochem 1982 122: 233-237. 